ORIGINAL ARTICLE

\title{
Weight and energy: parents' and children's perspectives on managing cystic fibrosis diet
}

\section{E Savage, P Callery}

See end of article for authors' affiliations

....................

Correspondence to: Dr E Savage, Senior Lecturer, School of Nursing and Midwifery, University College Cork, Cork, Ireland; e.savage@ucc.ie

Accepted

2 November 2004
Aims: To explore the meanings that parents and children attach to food and eating, and how these influence their approaches to dietary management of cystic fibrosis (CF).

Methods: Ethnographic design using in-depth interviews with 32 children with CF (aged 6-14 years) and their parents, and participant observations during visits to CF clinics with a sub-group of 21 children. Data were analysed using the constant comparative method and theoretical sampling was used to further explore and develop emergent themes.

Results: Dietary management was found to be a demanding task for children and their parents, and priorities differed between them. A priority of feeding for parents was to protect their children's long term physical health and survival by keeping their weight up. A challenge for parents was to ensure their children's cooperation with eating. A priority for children in being healthy was to have energy for physical activities and so energy rather than weight was of immediate relevance to their daily lives. These differences between parents and children gave rise to tensions and conflicts in their interactions with one another in managing diet.

Conclusions: Healthcare professionals should take account of the meanings that children and their parents attach to food and eating that can influence their decisions about implementing CF dietary recommendations. The role of children in making food choices has implications for acknowledging them as active participants in their dietary care and for adopting child centred approaches to dietary advice for CF.
Self management requires patients and their families to integrate CF care into their daily lives with consideration to the active role they take in determining, monitoring, and modifying therapies in collaboration with professionals. ${ }^{20}$ Effective self management education may depend on incorporating the objectives of patients and their families because these may differ from those of professionals. ${ }^{21}$ In the case of CF, there is little known about parents' and children's perspectives on implementing a high fat high calorie diet and about whether there are differences between professionals', parents', and children's objectives of dietary management. Drawing on a larger qualitative study, this paper reports on the meanings of food and eating to a group of school aged children with CF and their parents and how these influenced their approaches to dietary management.

\section{METHODS}

Children from middle childhood to early adolescence were selected because of unstable growth patterns in this group ${ }^{2}$ and because of their increasing independence from parents in making food choices ${ }^{19}$ Children were recruited from two CF centres in Ireland to maximise sample variation ${ }^{22}$ for age, sex, weight, and height centiles. This information was sourced by ES from children's case notes. In both centres, multidisciplinary teams managed CF care, and the overall approaches to dietary advice were similar, emphasising a high fat, high calorie diet.

Ethical approval was obtained from the relevant research ethics committees. An introductory letter about the study was sent to parents from the paediatric consultants. Information leaflets were mailed to children and parents following which ES contacted them by telephone to determine their willingness to participate in the study. Because theoretical sampling was used, the sample size was not determined at the outset. Therefore, following an initial selection of six approach to dietary management in school aged children. 
Table 1 Age and sex profiles of children

\begin{tabular}{lccl}
\hline & $6-8 y$ & $9-11 y$ & $12-14$ y \\
\hline Boys & 4 & 7 & 3 \\
Girls & 7 & 6 & 5 \\
Total & 11 & 13 & 8 \\
\hline
\end{tabular}

children and their parents, additional children and their parents were selected over the course of the study. Thirty two children with CF aged 6-14 years and their parents (mostly mothers) agreed and consented to taking part in the study. Maximum variation ${ }^{22}$ sampling was achieved including representatives of both sexes, across the age range (table 1) and across the range of weight for height centiles (table 2). Children had varied experiences of dietary supplementation; four children were currently receiving enteral feeds, and a further two had experienced these in the past. There were nine refusals, and although there were no obligations on children and parents to explain their reasons for refusal, some volunteered this information to include being "too busy", not wanting to expose children to talking about CF, and being involved in other CF research.

Audio recorded interviews with parents and with children separately were the principal method of data collection and were conducted by ES in participants' homes. Topic guides were used to focus the interviews on a range of issues of relevance to the research aim. These were used in an open and flexible manner to facilitate conversational style interviews that allowed children and parents to raise issues spontaneously. Children were invited to draw if they wished to put them at ease during interviews ${ }^{23}$ which some younger children accepted. Participant observation of clinic consultations was conducted by ES with a subset of 21 children using field notes and audio recordings to collect data. The purpose of observing clinic interactions was to further understand dietary advice given to parents and children and their experiences of clinic consultations. Analysis of these observations provided additional topics that were explored in interviews. Data analysis was carried out concurrently with data collection using a method of constant comparison. ${ }^{22}$ Interviews were transcribed in full and analysed by ES using a NUD*IST software package to manage the data. Data were coded and categorised by comparing and contrasting incidents moving from description to conceptualising to theorising about the data. ${ }^{22}$ Coding and categorising of data were reviewed by $\mathrm{PC}$, and through discussions agreement was reached between both authors. Theoretical sampling was used to explore and further develop emergent categories and

Table 2 Pattern of weight centiles for height of children plotted at clinic visit nearest date of interview

\begin{tabular}{|c|c|c|c|}
\hline Centile & Boys (n=13) & Girls (n= 19) & Total \\
\hline \multicolumn{4}{|c|}{ Consistent weight for height } \\
\hline (a) $>75 \mathrm{th}$ & 3 & 2 & 5 \\
\hline (b) 50 th to 75 th & 4 & 2 & 6 \\
\hline (c) 25 th to $<50$ th & 1 & 3 & 4 \\
\hline (d) 3 rd to $<10$ th & 0 & 2 & 2 \\
\hline \multicolumn{4}{|c|}{ Deviation in weight for *height } \\
\hline (e) 25 th to $<50$ th & 1 & 1 & 2 \\
\hline (f) 10 th to $<25$ th & 2 & 3 & 5 \\
\hline (g) 3 rd to $<10$ th & 2 & 5 & 7 \\
\hline (h) $<3$ rd & 0 & 1 & 1 \\
\hline \multicolumn{4}{|c|}{$\begin{array}{l}\text { *Height centile: (e) }>75 \text { th for both children; ( } f \text { ) } 50 \text { th to }<75 \text { th for } 1 \text { child, } \\
25 \text { th }<50 \text { th for } 4 \text { children; (g) } 25 \text { th }<50 \text { th for } 3 \text { children, } 10 \text { th to }<25 \text { th } \\
\text { for } 4 \text { children; (h) } 10 \text { th to }<25 \text { th for } 1 \text { child. }\end{array}$} \\
\hline
\end{tabular}

conceptual hypotheses ${ }^{22}$ (box 1). A reflexive approach to data collection and analysis was adopted, recognising that the interviewer (ES) was the "research tool" 24 and to limit the potential for introduction of bias. These data collection and analytical procedures contribute to the trustworthiness of analytical claims and to limiting threats to the validity of the data. ${ }^{25}$

\section{RESULTS}

\section{Parents' perspectives}

\section{Keeping the weight up}

A priority for parents in feeding their children was to protect their physical health and survival from the deteriorating effects of weight loss with CF. They spoke of professionals reinforcing this priority with an emphasis on a high fat diet. However, parents varied in their decisions about implementing this diet according to whether they saw their children gaining or losing weight. Parents who described their children as continuously gaining weight expressed caution about allowing them eat too much "fatty foods", and dietary advice emphasising high fat foods could be a source of tension if it breached their beliefs about healthy eating. Some mothers commented that "you have to give them an all round ... good diet" (Mother 06) similar "to the advice ... given to the population as a whole" (Mother 17). When children were gaining weight and having few chest infections, parents thought little about the progressive nature of $\mathrm{CF}$, and concerns about their physical health and survival stayed at the back of their minds.

The situation differed for parents who saw their children losing weight or being slow to gain weight, and they explained that worrying about their children's immediate and future health and survival was constantly on their minds. The experience of seeing children lose weight, especially rapid weight loss during chest infections, was described as very distressing. Parents explained that in these circumstances the importance they attached to weight gain and to a high fat diet was heightened:

Box 1: Examples of categories and conceptual hypotheses used in theoretical sampling of data

Children's perspectives

Category

- Being active and energetic

Conceptual hypotheses

- Children's daily experiences of energy seem important to how they define themselves as healthy

- Children's beliefs about weight may have little to do with the meanings they attach to being healthy

Parents' perspectives

Category

- Keeping the weight up

Conceptual hypotheses

- Parents' approaches to feeding their children vary according to their experiences of seeing them gaining or losing weight

- Keeping weight up is a priority for parents in maintaining their children's health status with CF 
She can eat what she likes, lots of fats, fries and sweets and bars, I don't mind because it helps to put weight up and keep her well, and after what we've been through, I mean to see her as a baby she was like a Biafran. (Mother 04)

\section{Ensuring children's cooperation with eating}

A challenge for parents was to ensure their children's cooperation with eating a high fat diet to maintain weight gain. Dietary advice from professionals was viewed by some parents as "grand in theory" but impractical to implement when children refused it. Children's refusal to eat a high fat diet became particularly distressing for parents when they saw them losing weight. Parents spoke of "getting strict", which some described as an effective strategy in getting children to increase their dietary intakes. Parents faced with the problem of their children continuing to refuse food, coupled with continuous weight loss, emphasised the need to heighten their efforts at getting them to eat. These parents described "battling" with their children and some felt compelled to "force feed". On reflection, these parents commented on force feeding as ineffective, and they welcomed having their children commenced on enteral tube feeding in order to keep their weight up:

\section{... there was no other avenue open to us at that time because I couldn't get her to eat and her weight was just falling off. (Mother 27)}

Implementing dietary advice for CF is therefore dependent on children's cooperation with eating because eating is an active process. In light of this, children's views are important, taking account of how the meanings they attach to food and eating influence their decisions about implementing dietary advice for CF.

\section{Children's perspectives}

Children spoke of "good food" and "bad food" and of the need to eat "good food" to grow and be strong. Some children, particularly younger ones, could not differentiate between the types of food that were good for children with CF compared to those who did not have CF, and taking enzymes was seen as the main difference between their diet and that of their peers. Most children aged 9 years and over viewed "fattening things" as good for CF to keep weight up and to help fight infections. However, some children described hearing conflicting messages about diet between the CF clinic and school, because dietary advice on high fat foods conflicted with learning about healthy foods at school that emphasised restricting "junk foods" high in fat content.

\section{Meanings of weight}

Although most older children described an awareness of weight gain as important to preventing chest infections, other children expressed uncertainty about why they needed to gain weight, implying that they were expected to implement dietary advice without understanding why. There was little indication in children's accounts to suggest that their dietary choices were motivated by a need to eat a high fat diet for weight gain. Although children talked about food in terms of what might be good or bad for them, in deciding what to eat they considered what they liked based on sensory qualities, especially taste. Children described eating as "a chore" when expected to eat food they disliked. Differences were observed between girls' and boys' accounts of foods they liked, with some girls describing a preference for lighter foods. Gender differences were also noted in the meanings children attached to weight in terms of body image. Boys emphasised the image of physique with reference to body strength and frame, whereas girls aged 8 years and older described images of thinness and fatness. For example, a 9 year old girl commented that "weight tells you how much fat you have" and "it shows you what kind of balance you are in, if you're too fat or too skinny" (Girl 27).

\section{Being active and energetic}

Unlike parents who spontaneously emphasised weight gain as a priority for their children's health, a priority for children was to have energy for physical activities every day. Energy was the criterion they used to describe their sense of health and wellbeing. They described having "energy for running around" when feeling well, whereas they described a lack of energy and a need "to lie down" when feeling unwell. Because children's accounts indicated that they could readily perceive energy changes, comparisons were made with their experiences of gaining or losing weight. Most children described difficulties in noticing weight changes apart from clothing size over time or weight checks at the clinic. Some children described being aware of changes in body weight; what was striking was that weight gain helped them have more energy for activities. However, energy rather than weight was what children emphasised as directly relevant to their health.

\section{DISCUSSION}

Although weight gain as a goal of CF dietary management has been highlighted in previous studies, there has been little understanding of parents' and children's perspectives on implementing a high fat diet and its relevance to health and wellbeing in CF. Parents and children differed in their perspectives with an emphasis on weight and energy respectively. Although professionals emphasised the recommended high fat CF diet, parents' decisions about implementing this diet arose primarily out of experiences of seeing their children lose weight, and they were cautious about implementing this diet if their children were thriving. This suggests that the meanings parents attach to weight as a criterion for judging health status in CF influence their approaches to dietary management. However, parents could experience practical difficulties in implementing the recommended CF diet because despite their heightened efforts at feeding, children could refuse this diet.

When children's views were considered, implementing dietary advice for CF could be difficult when it involved eating food they disliked. Unlike parents, children attached little meaning to weight and its implications for eating a high fat diet. It was energy that children described as important to their health because energy helped them be physically active in their daily lives. Energy was something they could experience changing in their bodies from day to day, whereas they had difficulties in knowing whether they were gaining or losing weight.

The findings have implications for professionals in helping parents and children implement the recommended high fat diet for CF. Differing priorities between parents and children suggest a need to consider the perspectives of both during CF clinic consultations with consideration to developing shared dietary plans that are child centred. Children need to be acknowledged as active participants in their dietary care because of their role in deciding whether to implement dietary advice. While remaining sensitive to parental concerns about weight and its implications for long term health and survival in CF, dietary advice could be tailored to a goal of increasing energy for daily activities rather than a goal of weight gain as a way of motivating children to eat. Putting less emphasis on weight gain and more on being active and 


\section{What is already known on this topic}

- A high fat high calorie diet contributes to improved growth, pulmonary function, and survival patterns in persons with CF

- Children's dietary intakes fall short of nutritional recommendations for CF

\section{What this study adds}

- The meanings that children and parents attach to food and eating influence their approaches to dietary management of CF

- Parents and children differ in the priorities they attach to being healthy with CF. Weight gain was a priority for parents, whereas having energy for physical activities was a priority for children

- Children take an active role in deciding whether to implement dietary advice, and so their perspectives need to be considered in the dietary management of CF

energetic would provide children with positive health messages that would be meaningful and relevant to their daily lives. The concept of energy could be used to enhance children's understandings of the importance of diet to their health with application to increased energy demands in the specific case of CF.

This in-depth study of a relatively small group of children identified factors that affected their dietary consumption. Further research is required to investigate how the meanings children and parents attach to dietary management of CF influence their decisions about implementing a high fat diet. The research agenda should also include school aged children's beliefs about body image and body weight, and how these and gender influence their dietary habits. Further research would be helpful to professionals in understanding and managing problems of inadequate dietary intakes previously reported across various ages groups, ${ }^{8-10}{ }^{12-14}$ and in girls compared to boys because of body image concerns. ${ }^{11}$

\section{ACKNOWLEDGEMENTS}

Eileen Savage acknowledges funding for the study through a Doctoral Scholarship awarded by An Bord Altranais (Nursing Board) Ireland from 1998 to 2000 and a Research Fellowship awarded by the Health Research Board, Ireland from 2000 to 2003.

\section{Authors' affiliations}

E Savage, Senior Lecturer, School of Nursing and Midwifery, University College Cork, Ireland
P Callery, Chair of Children's Nursing, School of Nursing, Midwifery and Health Visiting, University of Manchester, UK

Competing interests: none declared

\section{REFERENCES}

1 Corey M, McLaughlin F, Williams M, et al. A comparison of survival, growth, and pulmonary function in patients with cystic fibrosis in Boston and Toronto. J Clin Epidemiol 1988;41:583-91.

2 Zemel B, Jawad A, FitzSimmons S, et al. Longitudinal relationship among growth, nutritional status, and pulmonary function in children with cystic fibrosis: analysis of the Cystic Fibrosis Foundation National CF Patient Registry. J Pediatr 2000;137:374-80.

3 Steinkamp G, Wiedemann B. Relationship between nutritional status and lung function in cysti c fibrosis: cross sectional and longitudinal analyses from the German CF quality assurance (CFQA) project. Thorax 2002;57:596-601.

4 Sharma R, Florea V, Bolger A, et al. Wasting as an independent predictor of mortality in patients with cystic fibrosis. Thorax 2001;56:746-50.

5 Ramsey B, Farrell P, Pencharz P. Nutritional assessment and management in cystic fibrosis: a consensus report. The Consensus Committee. Am J Clin Nutr 1992;55:108-16.

6 Sinaasappel M, Stern M, Littlewood J, et al. Nutrition in patients with cystic fibrosis: a European consensus. J Cystic Fibrosis 2002;1:51-75

7 Borowitz D, Baker R, Stallings V. Consensus report for pediatric patients with cystic fibrosis. J Pediatr Gastroenterol Nutr 2002;35:246-59.

8 Stark L, Jelalian E, Mulvihill M, et al. Eating in preschool children with cystic fibrosis and healthy peers: behavioral analysis. Pediatrics 1995;95:210-15.

9 Stark L, Jelalian E, Mulvihill M, et al. Descriptive analysis of eating behavior in school-age children with cystic fibrosis and healthy control children. Pediatrics 1997;99:665-71

10 Anthony H, Bines J, Phelan P, et al. Relation between dietary intake and nutritional status in cystic fibrosis. Arch Dis Child 1998;78:443-7.

11 Collins C, O'Loughlin E, Henry R. Discrepancies between males and females with cystic fibrosis in dietary intake and pancreatic enzyme use. J Pediatr Gastroenterol Nutr 1998;26:258-62.

12 Powers S, Patton S, Byars K, et al. Caloric intake and eating behavior in infants and toddlers with cystic fibrosis. Pediatrics 2002;109:e75-5.

13 Crist W, McDonnell P, Beck M, et al. Behavior at mealtimes and the young child with cystic fibrosis. Dev Behav Pediatr 1994;15:157-61.

14 Sanders M, Turner K, Wall C, et al. Mealtime behavior and parent-child interaction: a comparison of children with cystic fibrosis, children with feeding problems, and nonclinic controls. J Pediatr Psychol 1997;22:881-900.

15 Stark L, Jelalian E, Powers S, et al. Parent and child mealtime behavior in families of children with cystic fibrosis. J Pediatr 2000;136:195-200.

16 Singer L, Nofer J, Benson-Szekely L, et al. Behavioral assessment and management of food refusal in children with cystic fibrosis. Dev Behav Pediatr $1991 ; 12: 115-20$.

17 Stark L, Powers S, Jelalian E, et al. Modifying problematic mealtime interactions of children with cystic fibrosis and their parents via behavioral parent training. J Pediatr Psychol 1994;19:751-68.

18 Stark L, Mulvihill M, Powers S, et al. Behavioral intervention to improve calorie intake of children with cystic fibrosis: treatment versus wait list control. J Pediatr Gastroenterol Nutr 1996;22:240-53.

19 Ross S. Do I really have to eat that? A qualitative study of schoolchildren's food choices and preferences. Health Educ J 1995;54:312-21.

20 Bartholomew L, Czyzewski D, Parcel G, et al. Self-management of cystic fibrosis: short-term outcomes of the Cystic Fibrosis Family Education Program. Health Educ Behav 1997;24:652-66.

21 Milnes L, Callery P. The adaptation of written self-management plans for children with asthma. J Adv Nurs 2003;41:444-53.

22 Strauss A, Corbin J. Basics of qualitative research: techniques and procedures for developing grounded theory. London: Sage Publications, 1998.

23 Hill M. Participatory research with children. Child Fam Soc Work 1997;2:171-83.

24 Sword W. Accounting for presence of self: reflections on doing qualitative research. Qual Health Res 1999;9:270-8.

25 Hammersley M, Atkinson, P. Ethnography: principles and practice. London: Routledge, 1995 